\title{
The right combination
}

Science 362, 1276-1281 (2018)

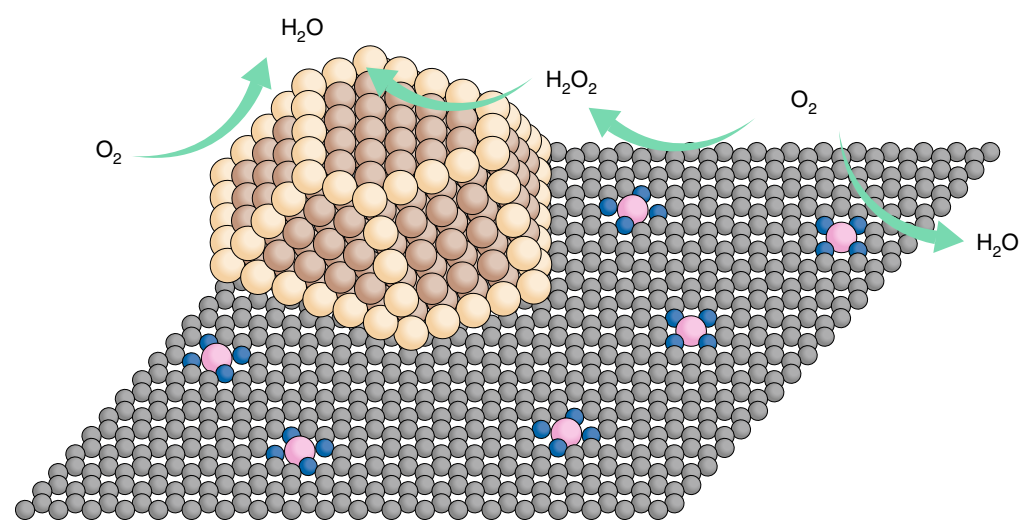

Proton-exchange membrane fuel cells (PEMFCs) hold high promise for their use in the automotive industry. Some car manufacturers have already started commercializing hydrogen-fuelled vehicles based on such technology. However, it is estimated that around $45 \%$ of the cost of a PEMFC concerns the use of platinum for its anode and cathode catalysts. Whereas several alternatives exist to drive the hydrogen oxidation reaction at the anode at minimal expense in performance, intensive research efforts currently focus on finding efficient catalysts for the kineticallyhindered oxygen reduction reaction (ORR) at the cathode. The potential largescale implementation of this technology mostly relies on minimizing the amount of platinum or other precious metals to effectively reduce the cost.

Now, Di-Jia Liu and co-workers at Argonne National Laboratory, in collaboration with researchers at Purdue University and Shanghai Jiao Tong University, combine two of the most active ORR catalysts, namely platinum-cobalt alloys and cobalt dispersed on nitrogen-doped carbon (Co-N-C), to boost the ORR performance while decreasing the Pt content below $3 \mathrm{wt} \%$. The resulting catalysts meet the mass activity and activity loss 2020 technical targets of the US Department of Energy (DOE).
The researchers present two catalysts prepared from Co- and $\mathrm{Zn}$-containing zeolitic imidazolate frameworks, which result in $\mathrm{PtCo}$ or $\mathrm{Pt}_{3} \mathrm{Co}$ nanoparticles that co-exist with atomically dispersed Co- $\mathrm{N}_{x}$ and Co nanoparticles encapsulated by onion-like graphitic layers. Both catalysts deliver excellent ORR activity in both acidelectrolyte rotating electrode and PEMFC configurations. In particular, the PEMFC mass activities at $0.9 \mathrm{~V}_{\mathrm{iR} \text {-free }}$ are 1.77 and $1.08 \mathrm{~A} \mathrm{mg}_{\mathrm{Pt}}{ }^{-1}$ for the $\mathrm{Pt}_{3} \mathrm{Co}$ - and PtCobased catalysts, respectively, both meeting the $0.44 \mathrm{~A} \mathrm{mg}_{\mathrm{Pt}^{-1}}{ }^{-1} \mathrm{DOE} 2020$ target. After 30,000 cycles of accelerated stress tests the $\mathrm{Pt}_{3} \mathrm{Co}$-based catalyst retained $14 \%$ of its initial activity whereas the PtCo-based catalyst retained $64 \%$ of its initial value, the latter also complying with the DOE 2020 target (<40\% loss). Density functional theory calculations show that the $\mathrm{Pt}-\mathrm{Co}$ nanoparticles catalyse the direct ORR and also facilitate the reduction of $\mathrm{H}_{2} \mathrm{O}_{2}$ generated on nearby Co-N-C sites, which not only increases the activity but also the durability of the catalyst, because $\mathrm{H}_{2} \mathrm{O}_{2}$ is known to corrode $\mathrm{Co}-\mathrm{N}-\mathrm{C}$ catalysts.

\section{Marçal Capdevila-Cortada}

Published online: 14 January 2019 https://doi.org/10.1038/s41929-018-0222-2 